\title{
Estimating landscape structure effects on pollination for management of agricultural landscapes
}

\author{
Ehsan Rahimi ${ }^{1}$, Shahindokht Barghjelveh ${ }^{1^{*}}$ (D) and Pinliang Dong ${ }^{2}$
}

\begin{abstract}
Background: The growing human population around the world is creating an increased demand for food. In agricultural landscapes, forests are cleared and turned into agricultural land to produce more food. Increasing the productivity of agricultural land per unit area may prevent extreme forest degradation. Since many agricultural products are dependent on pollinators, it is possible to increase crop production by increasing the pollination rate in the agricultural landscapes. Pollinators are highly dependent on forest patches in agricultural landscapes. Therefore, by creating new forest patches around agricultural fields, we can increase the pollination rate, and thus the crop production. In this regard, estimating the effects of different scenarios of forest fragmentation helps us to find an optimized pattern of forest patches for increasing pollination in an agricultural landscape.
\end{abstract}

Methods: To investigate the effect of different forest fragmentation scenarios on pollination, we used simulated agricultural landscapes, including different forest proportions and degrees of fragmentation. Using landscape metrics, we estimated the relationship between pollination and landscape structure for each landscape.

Results: Our results showed that for increasing pollination, two significant factors should be considered: habitat amount and capacity of small patches to supply pollination. We found that when the capacity of small patches in supplying pollination was low, fragmented patterns of forest patches decreased pollination. With increasing capacity, landscapes with a high degree of forest fragmentation showed the highest levels of pollination. There was an exception for habitat amounts (the proportion of forest patches) less than 0.1 of the entire landscape where increasing edge density, aggregation, and the number of forest patches resulted in increasing pollination in all scenarios.

Conclusion: This study encourages agriculturists and landscape planners to focus on increasing crop production per unit area by pollinators because it leads to biodiversity conservation and reduces socio-economic costs of land-use changes. We also suggest that to increase pollination in agricultural landscapes by creating new forest patches, special attention should be paid to the capacity of patches in supporting pollinators.

Keywords: Landscape ecology, Pollination, Landscape metrics, Simulated landscapes, Small forest patches

\section{Introduction}

Considering the global population growth, it has been argued that agricultural production should increase by $70 \%$ by 2050 (Bruinsma 2009). The second goal of the

\footnotetext{
*Correspondence: s-barghjelveh@sbu.ac.ir

1 Environmental Sciences Research Institute, Shahid Beheshti University, Tehran, Iran

Full list of author information is available at the end of the article
}

Sustainable Development Goals (SDGs) also aims to end hunger, achieve food security and improved nutrition, and promote sustainable agriculture (Assembly 2015). These goals would need more arable land in agricultural landscapes which may lead to continued deforestation (Keenan et al. 2015). Agricultural production is not only dependent on soil fertility, water quality, and pest regulation, but also related to biodiversity such as 
the presence of pollinators in agricultural farms (Blitzer et al. 2012). Crop pollination by bees is one of the wellrecognized ecosystem services in agricultural landscapes, which plays a key role in global food production (Bentrup et al. 2019; Potts et al. 2016). More than 35\% of world food production comes from agricultural products that are highly dependent on pollinators (Klein et al. 2007). Therefore, we can improve production per unit area through increasing pollination rather than expanding agricultural land. Bees are more efficient pollinators than other pollinators because they visit more flowers and put more pollen on the flower's stigma (Willmer et al. 2017). Approximately $9.5 \%$ of the world's agricultural production comes from the services provided by wild bees (Gallai et al. 2009).

To increase pollination in agricultural landscapes, it is critical to understand how wild bees are affected by habitat quality and landscape structure (Olsson et al. 2015; Syrbe and Walz 2012). Wild bees required two basic habitats: nesting habitat and foraging habitat (Olsson et al. 2015; Ricketts et al. 2008). The proximity of these habitats is an important attribute of the landscape for pollination (Kline and Joshi 2020). In agricultural landscapes, pollination depends on the movement of native pollinators from non-agricultural areas such as forests (nesting habitat) to farms (foraging habitat) (Ricketts et al. 2008). It is acknowledged that the abundance and diversity of wild bees in farms depends on the distance between their nesting and foraging habitat patches (Ekroos et al. 2013; Gathmann et al. 1994; Ricketts et al. 2008; SteffanDewenter 2002; Steffan-Dewenter and Schiele 2008). Therefore, landscape structure characteristics (such as the size, arrangement, and shape of patches) significantly affect wild bees (Syrbe and Walz 2012). The arrangement of suitable nesting patches and the ability of pollinators to move from these patches to surrounding farms affect the pollination rate in agricultural landscapes (Mitchell et al. 2013). Habitat connectivity also affects the abundance and diversity of pollinators which decreases in fragmented patterns of forest patches (Mitchell et al. 2014; Potts et al. 2010).

It is possible to manage the ecosystem services provision by creating new patches and optimizing their location (Fahrig et al. 2011). Therefore, creating new vegetation in a landscape is an issue that deserves to be considered as a research priority (Munro et al. 2009; Thomson et al. 2009). In landscapes that experienced drastic changes and the remaining habitats are highly fragmented, creating new habitat patches can provide a new habitat alongside the remaining patches (Crossman et al. 2016). For example, restoring a forest habitat to make a connection between the remaining patches improves functional diversity (Craven et al. 2016). Since wild bees are highly dependent on forest patches as a nesting habitat in agricultural landscapes (Olsson et al. 2015), it is possible to attract more populations from pollinators by creating new forest patches. However, the effects of changing the location and size of natural habitats like a forest in providing pollination to the surrounding agricultural lands have not been studied (Mitchell 2014). How much habitat is needed and how it should be distributed within an agricultural landscape is the most important question in this area (Brosi et al. 2008b). Maurer et al. (2020) emphasized the importance of studying the effects of fragmentation on pollinators to guide the spatial optimization of landscapes to increase pollination.

Pollination provision occurs when natural and artificial habitats have some juxtaposition, and this juxtaposition occurs when there are some habitat loss and fragmentation in the landscape (Eigenbrod 2016). Some studies have found high pollination rates in fragmented patterns of forest patches (Brosi et al. 2008a). However, other studies have found adverse effects of forest fragmentation on pollination. For example, Farwig et al. (2009) reported a decrease in pollination success in landscapes with high isolation of forest patches. Aguilar et al. (2006) found that reducing the patch size and increasing the isolation of the patches adversely affected pollination. They reviewed 54 studies examining the effects of fragmentation on plant reproduction and found adverse effects of fragmentation on reproduction, mainly due to fragmentation effects on pollinators. Mitchell et al. (2015) predicted that the highest levels of pollination occurred in landscapes with moderate habitat amounts and fragmentation levels. Adverse effects of fragmentation are more impressive at low habitat amounts, mainly in landscapes that habitat covers less than approximately $20-30 \%$ of the entire landscape (Fahrig 2003; Maurer et al. 2020; Rybicki and Hanski 2013). At low habitat amounts, Maurer et al. (2020) reported the adverse effects of fragmentation on bumblebee colony size. However, they found positive effects at high habitat amounts. Bee foraging activity also increased in the landscapes with a low degree of fragmentation. They reported that the effects of fragmentation were strongly dependent on habitat amount in the landscapes. Rahimi et al. (2021) showed that the effects of forest fragmentation on pollination were completely different at the landscape and farm levels.

The main purpose of this study is to find an optimized pattern of forest patches to increase pollination in an agricultural landscape in northern Iran. Land managers are interested to know what factors are essential for increasing pollination by creating new forest patches in the study area. The most important question that we intend to address is: which pattern of new forest patches provides the highest pollination level in the landscape? 
As mentioned above, it is unclear what pattern of forest patches (aggregated or fragmented) leads to the highest pollination rate in a given habitat amount. Since it is difficult and time-consuming to examine the effects of creating new forest patches in an agricultural landscape, simulation-based studies are recommended (Häussler et al. 2017). Therefore, this study uses simulated landscapes for modeling the effects of forest patterns on pollination at a certain amount of habitat. We first determine these effects using simulated landscapes and then predict the suitable pattern of new forest patches for maximizing pollination in the landscape under study.

\section{Materials and methods}

\section{Generating simulated landscapes}

In landscape ecology, instead of using real landscapes, many studies have simulated the ecological processes of a landscape based on computer models (van Strien et al. 2016). Using simulated landscapes, we can examine certain aspects of a landscape. In this study, we used the nlm_randomcluster function presented in the NLMR package (Sciaini et al. 2018) in $\mathrm{R}$ software to generate simulated agricultural landscapes, including two ecosystems of forest and agriculture. The output maps had dimensions of 50 by 50 cells and contained different proportions of forest habitat and degree of forest fragmentation. The proportions of forest habitat varied from $0.05 \%$ to $50 \%(0.05,0.1,0.2,0.3,0.4$, and 0.5$)$ of the entire landscape. At each of these proportions, the degree of fragmentation changed from the highest $(0.01)$ to the lowest (0.5) using parameter $p$ (the proportion of elements randomly selected to form clusters) in the NLMR package.

\section{Estimating pollination in simulated landscapes}

Large patches maintain more pollinators (Aguirre and Dirzo 2008; Tscharntke and Brandl 2004), and pollinators' abundance decreases, as the distance from large patches increases (Donaldson et al. 2002; Joshi et al. 2016; Mitchell et al. 2014; Ricketts et al. 2008). Therefore, in this study, it was assumed that pollination rate is a function of the patch size and larger patches provide more services than smaller ones. The potential of a patch to provide pollination is calculated according to the following equation, with an output between 0 and 1 (Mitchell et al. 2015):

$$
N_{j=1-\exp \left[-\left(A_{j} * p\right)\right]},
$$

where $A_{j}$ represents the patch area and $p$ is a fixed number to determine the curve steepness. Using this equation, the ecosystem service supply for each patch is calculated from the patch area. Increasing $p$ gives the small patches more capacity to provide pollination. In this study, we used different values of $p(0.001,0.008$, $0.02,0.08$, and 0.16 ) to better adapt our results to the real conditions in nature (Mitchell et al. 2015).

Several studies have shown that pollination decreases exponentially with distance from natural and semi-natural patches within agricultural fields (Keitt 2009; Martins et al. 2015; Mitchell et al. 2015; Ricketts et al. 2008). For example, Ricketts et al. (2008) reviewed 23 studies examining the effects of landscape structure on pollination. They found that the abundance and visiting rate of pollinators decreased exponentially as the distance from the nesting habitat increased. The distance that bees can travel affects their ability to pollinate. This foraging distance varies according to the species and body size (Everaars et al. 2018). For example, Apis mellifera can travel up to $1100 \mathrm{~m}$ (Gary et al. 1981), but most bees move short distances below their maximum capacity, in fact, something between 100 and $300 \mathrm{~m}$ (Greenleaf et al. 2007; Zurbuchen et al. 2010). In many agricultural landscapes, the abundance and diversity of bees reduce at distances of 50 to $500 \mathrm{~m}$ from forest patches (Bailey et al. 2014). For example, for the coffee plant, pollination reduces with increasing distance from forest patches (Boreux et al. 2013; Klein et al. 2003; Krishnan et al. 2012; Ricketts et al. 2004; Saturni et al. 2016). Therefore, wild bees only pollinate the crops that are within their foraging distances (Ricketts et al. 2006). Pollination flow from forest patches to surrounding farms was calculated by the following equation (Mitchell et al. 2015):

$$
\sum i j(d)=N_{j} * 2^{-\left(\frac{d}{d 1 / 2}\right)},
$$

where $N_{j}$ is the value that extends from the desired patch to the surrounding environment, $d_{1 / 2}$ is a constant that determines the distance at which the pollination rate reaches $1 / 2$ of its original value. In this study, we used different distance values of $5,10,15$, and 20 cells from the edge of the patches to identify the effects of distance change on pollination behavior.

\section{Estimating landscape structure effects on pollination}

Landscape metrics measure two fundamental aspects of landscape structure: composition and configuration. Landscape composition refers to the variety and abundance of patch types regardless of their spatial distribution, while landscape configuration refers to the spatial elements or distribution of landscape components (Leitão et al. 2012). Each simulated landscape has a different structural pattern and therefore different pollination rates. To quantify landscape structure, we calculated six landscape metrics for all simulated landscapes using Fragstats software (McGarigal et al. 2002) at the class level. These metrics included mean patch 
Table 1 Descriptions of the selected landscape metrics

\begin{tabular}{|c|c|c|c|}
\hline Category & Metric & Equation & Range \\
\hline \multicolumn{4}{|l|}{$\begin{array}{l}\text { Area and } \\
\text { edge }\end{array}$} \\
\hline & Area-MN & $\frac{\sum_{j=1}^{n} x_{i j}}{n_{i}}$ & Area-MN $>0$ \\
\hline & ED & $\frac{\sum e_{i k}}{A}(10000)$ & $0 \leq \mathrm{ED}$, no limit \\
\hline \multirow[t]{2}{*}{ Shape } & \multirow[t]{2}{*}{ PAFRAC } & $\stackrel{2}{\left[\sum_{j=1}^{n} \ln p_{i j}-\ln a_{i j}\right]}-\left[\left(\sum_{j=1}^{n} \ln p_{i j}\right)\left(\left(\sum_{j=1}^{n} \ln a_{i j}\right)\right)\right]$ & \multirow[t]{2}{*}{$1 \leqq P A F R A C \leqq 2$} \\
\hline & & $\left(\sum_{j=1}^{n} \ln p_{i j}^{2}\right)-\left(\sum_{j=1}^{n} \ln p_{i j}^{2}\right)^{2}$ & \\
\hline \multirow[t]{3}{*}{ Aggregation } & Al & $\left(\frac{g_{i i}}{\max \rightarrow g_{i i}}\right)(100)$ & $0 \leq \mathrm{Al} \geq 100$ \\
\hline & NP & $n_{i}$ & $N P \geq 1$ \\
\hline & ENN & $h_{i j}$ & $E N N>0$ \\
\hline
\end{tabular}

$a_{i j}=$ area $\left(\mathrm{m}^{2}\right)$ of patch; $A=$ total landscape area $\left(\mathrm{m}^{2}\right) ; n_{i}=$ number of class $i$ patches in the landscape; $e_{i j}=$ total length $(\mathrm{m})$ of edges of patch $i j$, including landscape boundary, $g_{i i}=$ the number of adjacencies (contiguity) between pixels of patch class $i ; \max g_{i i}=$ maximum possible number of adjacencies among pixels of patches of class $i, h_{i j}=$ distance $(\mathrm{m})$ from patch $i j$ to the nearest neighboring patch of the same type (class), based on patch edge-to-edge distance, computed from cell center to cell center (McGarigal et al. 2002)

In this table, several metrics related to area and edge, shape, and aggregation categories have been presented that all of them measure landscape configuration aspects

area (Area-MN), edge density (ED), perimeter-area fractal dimension (PAFRAC), aggregation (AI), number of patches (NP), and mean Euclidean nearest-neighbor distance (ENN) (Table 1). The Pearson correlation was used to determine the degree of dependency of pollination variations to landscape patterns.

\section{Using a genetic algorithm for creating new forest patches}

In this study, a genetic algorithm was used to optimize pollination by creating new patches in the study area, consisting of two forest and agricultural ecosystems. The genetic algorithm is one of the most widely used methods in finding the optimal solution among the countless solutions for land planning (Matthews et al. 2006) and is based on evolutionary calculations (Mitchell et al. 1994). Equation 2 was considered as the goal function of the genetic algorithm, and the purpose was to maximize this function with different values of $p$. We also considered the spatial scale effects on the locations of the new patches. Therefore, this simulation was performed at four spatial scales with different total landscape areas and forest proportions. For each landscape, the area of new forest patches was considered $5 \%$ of the total selected landscape (Fig. 1).

\section{Results}

\section{Effects of small forest patches on pollination}

Figure 2 illustrates the pollination changes according to the degree of fragmentation in different forest proportions and $p$ values. As can be seen in Fig. 2, the horizontal axes show the degree of fragmentation that decreases from 0.1 to 0.5 , while the vertical axes indicate estimated pollination at the farm level. The results in Fig. 2 suggest that pollination behavior changed linearly and non-linearly depending on the variations in landscape structure patterns. The pollination behavior did not change due to the distance from forest patches or the bees' foraging range. The capacity of small patches in supplying pollination and the proportion of forest patches were affecting factors determining the position of the maximum pollination rate in the graphs (Fig. 2).

At $p=0.001$ (low capacity of small patches in supplying pollination) in all forest proportions $(0.05,0.1,0.2$, $0.3,0.4$, and 0.5 ) of the total landscape, high levels of forest fragmentation led to declining pollination. When the forest proportions were less than 0.3 , this behavior was linear, and when the forest proportions were 0.4 or 0.5 , the behavior became non-linear. At $p=0.004$ and 0.008 with forest proportions less than 0.3 , an increase in fragmentation led to a decrease in pollination. When the forest proportions were 0.4 and 0.5 , the pollination behavior changed slightly and became non-linear, in which the maximum pollination rate of 0.5 occurred at moderate degrees of fragmentation. At $p=0.02$ in all forest proportions, the pollination behavior changed non-linearly and altered the position of the maximum pollination rate in the graph (Fig. 2). At $p=0.08$, with a forest proportion of 0.5 , the maximum pollination level occurred in landscapes with the highest fragmentation level. At $p=0.16$ (high capacity of small patches in supplying pollination), with forest proportions being 0.05 and 0.1 , the maximum pollination rate occurred at the moderate degrees of fragmentation. When forest proportions were greater than 0.3 , the maximum pollination rate occurred in the highest fragmentation level. Generally, the most notable result was that in the low capacities of small forest patches in supplying pollination, the maximum pollination level happened in the landscapes with a low degree of fragmentation. It should be emphasized that the high capacities of the small patches changed the result completely.

\section{The relationship between forest fragmentation and pollination}

Table 2 shows the results of correlation analysis between pollination and landscape metrics for different $p$ and forest proportions. The statistical analyses indicated that the capacity of small patches in supplying pollination and different forest amounts affected the effects of fragmentation on pollination considerably. In each habitat proportion with a specific value of $p$, the relationship between landscape metrics and pollination was different. As the fragmentation decreases, the number of patches (NP), edge density (ED), and the perimeter-area ratio 


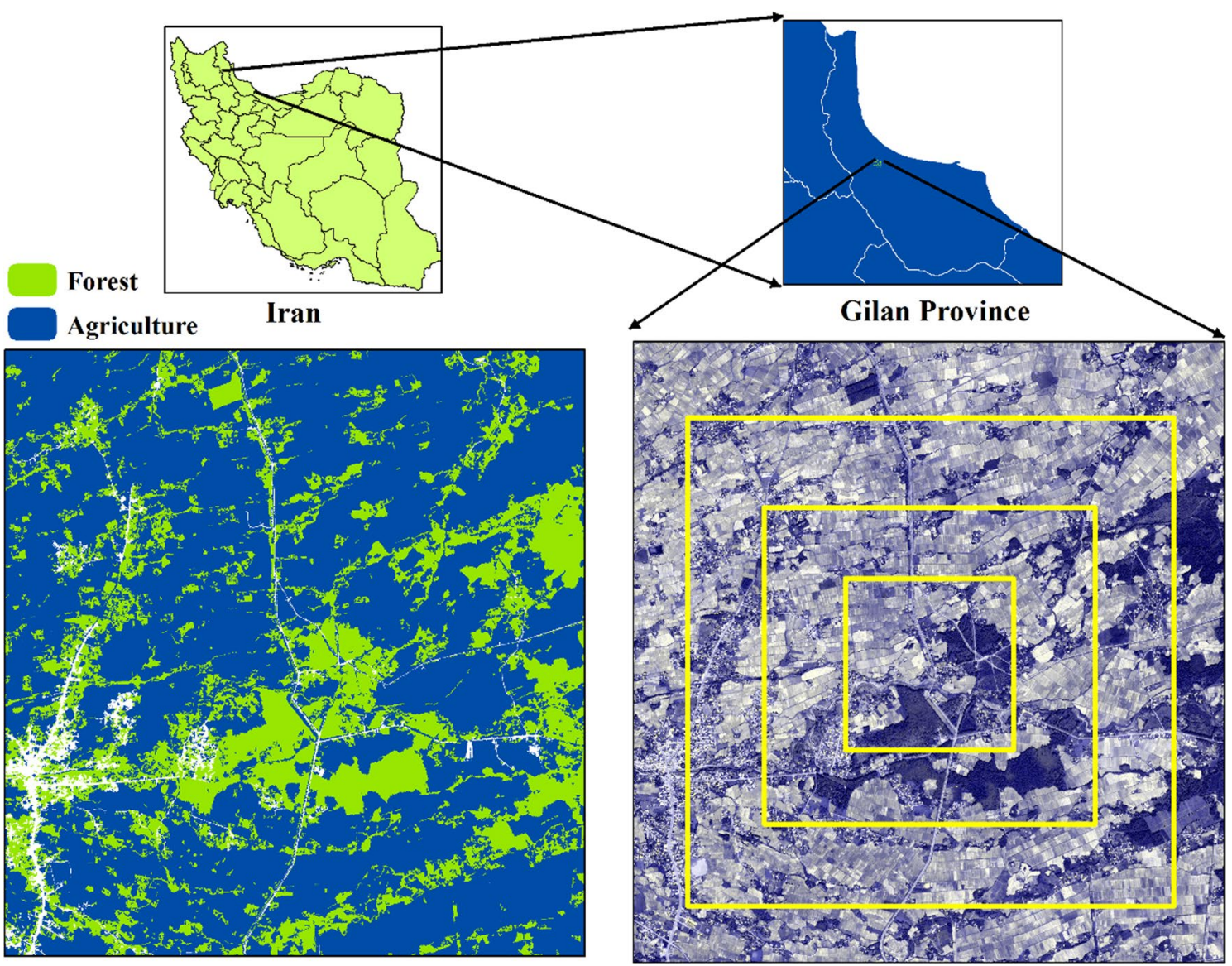

Fig. 1 Location of the study area in Iran and Gilan province. The image on the right shows an aerial photo of the study area, and four subsets for creating new patches have been drawn by yellow lines at four different spatial scales on the left. The image on the left shows the land cover map including forest and agricultural ecosystems that were obtained from the aerial photo

(AREA_MN) of the patches decreases, while the average distance between the patches (ENN-MN) and the patches' aggregation (AI) increases.

AI measures the aggregation degree of patches, and it is high when patches have an aggregated pattern. This metric showed a strong positive correlation with pollination when $p$ was less than 0.008 in all forest proportions. When $p$ was less than 0.008 in all proportions, the number of patches (NP) showed a negative correlation with pollination, implying that reducing the number of patches increased pollination. When forest proportions were greater than 0.2 and $p$ was higher than 0.8 , the result was different (Table 2). The positive correlation between ENN_MN and pollination showed that at $p$ less than 0.008 , increasing the distance between patches increased pollination. LPI and AREA MN also showed a positive correlation with pollination at $p$ less than 0.08 in all proportions, implying that increasing the mean patch area increased pollination. However, when $p$ was higher than 0.08, the result was different. ED and PAFRAC had a strong positive correlation with pollination. The results of these metrics showed that at $p$ less than 0.008 , increasing the edge density and shape complexity of patches reduced pollination, and by increasing the value of $p$ to 0.08 , this effect was reversed. However, when forest proportions were less than 0.1 , there were exceptions for both metrics (Table 2).

\section{The role of creating new forest patches in increasing pollination}

Figure 3 shows the location of the new patches created by the genetic algorithm with two spatial extents. In this part of the research, the aim was to determine the location, shape, and number of new forest patches in the study area to increase pollination. Row A (Fig. 3) shows the original images, row $\mathrm{B}$ shows the created patches at $p=0.16$, and row $C$ shows the created patches at $p=0.001$. The results of this section also showed that 

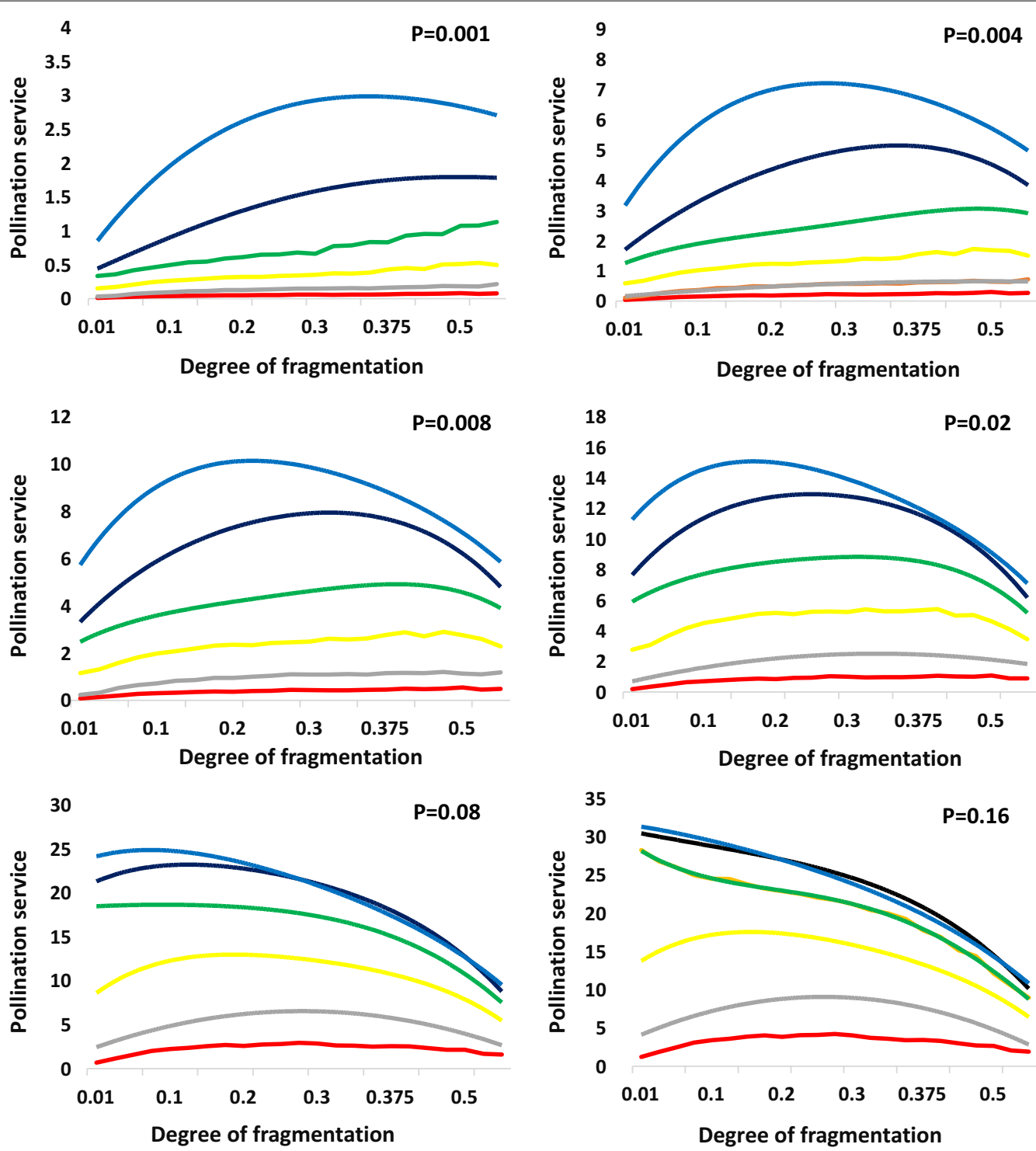

$\begin{array}{lllll}-0.05 & -0.1 \quad 0.2 \quad-0.3 \quad-0.4 \quad-0.5\end{array}$

Fig. 2 Pollination shifts according to forest fragmentation level and small patches' capacity in supplying pollination. In this figure, horizontal axes show the degree of fragmentation and vertical axes indicate estimated pollination at the farm level. Fragmentation decreases the pollination services at $p=0.001$ while it increases pollination at higher $p$ values. The shift in the position of the maximum level of pollination from $p=0.001$ to $p=0.16$ is obvious

when the capacity of small forest patches in supplying pollination was low, the created patches were located near the original natural patches in the landscape. As the capacity of the small patches increased, the created patches were distributed sparsely in the landscape, as can be seen in subset 1 (the left portion of Fig. 3). The change in spatial scale caused a shift in the locations of created patches in each subset, as predicted. As the spatial extent increased, the proportion of the original habitat also changed, and as a result, the shape and location of the new patches changed.

\section{Discussion}

The capacity of small patches in supplying pollination Our results showed that the effects of forest fragmentation on pollination were influenced by two main factors: (1) the capacity of small patches in supplying pollination and (2) the proportion of the landscape occupied by forest patches or simply habitat amount. In general, when the capacity of small patches in providing pollination was insignificant, fragmentation decreased pollination. As the capacity increased, landscapes with a fragmented pattern of forest patches acquired higher levels of pollination. The 
Table 2 Correlation between landscape metrics and pollination at different $p$ and habitat areas

\begin{tabular}{|c|c|c|c|c|c|c|c|}
\hline & Proportion & PAFRAC & ED & AREA_MN & ENN_MN & NP & Al \\
\hline \multirow[t]{6}{*}{$P=0.001$} & 0.05 & 0.66 & -0.98 & 0.85 & 0.87 & -0.96 & 0.98 \\
\hline & 0.1 & 0.46 & -0.99 & 0.85 & 0.88 & -0.97 & 0.99 \\
\hline & 0.2 & -0.70 & -0.96 & 0.92 & 0.92 & -0.90 & 0.96 \\
\hline & 0.3 & -0.92 & -0.94 & 0.97 & 0.96 & -0.85 & 0.94 \\
\hline & 0.4 & -0.79 & -0.95 & 0.84 & 0.77 & -0.94 & 0.95 \\
\hline & 0.5 & -0.65 & -0.97 & 0.71 & 0.55 & -0.93 & 0.87 \\
\hline \multirow[t]{6}{*}{$P=0.008$} & 0.05 & 0.72 & -0.97 & 0.76 & 0.78 & -0.98 & 0.97 \\
\hline & 0.1 & 0.55 & -0.96 & 0.68 & 0.71 & -0.99 & 0.96 \\
\hline & 0.2 & -0.58 & -0.93 & 0.74 & 0.75 & -0.96 & 0.96 \\
\hline & 0.3 & -0.57 & -0.86 & 0.55 & 0.52 & -0.92 & 0.86 \\
\hline & 0.4 & -0.18 & -0.57 & 0.20 & 0.08 & -0.74 & 0.57 \\
\hline & 0.5 & -0.83 & -0.08 & 0.85 & 0.73 & -0.97 & 0.97 \\
\hline \multirow[t]{6}{*}{$P=0.08$} & 0.05 & 0.68 & -0.50 & 0.003 & -0.03 & -0.64 & 0.50 \\
\hline & 0.1 & 0.37 & -0.31 & -0.23 & -0.19 & -0.48 & 0.31 \\
\hline & 0.2 & 0.46 & 0.32 & -0.75 & -0.74 & 0.12 & -0.32 \\
\hline & 0.3 & 0.89 & 0.75 & -0.97 & -0.98 & 0.58 & -0.75 \\
\hline & 0.4 & 0.90 & 0.71 & -0.94 & -0.97 & 0.52 & -0.71 \\
\hline & 0.5 & 0.94 & 0.82 & -0.96 & -0.98 & 0.65 & -0.82 \\
\hline \multirow[t]{6}{*}{$P=0.16$} & 0.05 & 0.53 & -0.24 & -0.27 & -0.24 & -0.40 & 0.24 \\
\hline & 0.1 & 0.22 & -0.07 & -0.45 & -0.42 & -0.24 & 0.06 \\
\hline & 0.2 & 0.59 & 0.59 & 0.91 & -0.90 & 0.41 & -0.59 \\
\hline & 0.3 & 0.95 & 0.90 & -0.99 & -0.99 & 0.78 & -0.90 \\
\hline & 0.4 & 0.96 & 0.86 & -0.99 & -0.99 & 0.71 & -0.86 \\
\hline & 0.5 & 0.96 & 0.89 & -0.99 & -0.98 & 0.74 & -0.89 \\
\hline
\end{tabular}

At $p$ below 0.008 , fragmented patterns of forest patches reduce pollination service, but at higher values of $p$, aggregated patterns increase pollination

combined effects of $p$ and the habitat amount altered the position of maximum pollination in the graphs. Mitchell et al. (2015) also found that increasing the capacity of small patches to supply ecosystem services changed the position of maximum services (peaks). When increasing this capacity, the peaks occurred at high ranges of habitat amount. It is noteworthy that Mitchell et al. (2015) merely examined the effects of habitat loss on distancedependent services such as pollination, and did not evaluate the effects of fragmentation on ecosystem services.

Increasing the values of $p$ in Eq. 1 implies that small patches could have an equal capacity to large patches in providing pollination. In this regard, the patches' capacity in supplying pollination was set between 0 and 1 , which indicated the maximum capacity of 1 . For example, at $p=0.001$, a patch containing 2300 cells had a capacity of 0.9 in providing pollination, while at $p=0.008$, this capacity occurred for a patch with 300 cells. Such patches in the simulated landscapes in this study constituted $0.12 \%$ of the entire landscape. As the value of $p$ increased, the capacity of small patches was at the same level as the larger patches, which was almost unexpected. For example, at $p=0.16$, the patches including 15 cells had a capacity of 0.90 , and a patch with 90 cells had the maximum capacity (1.0) to provide pollination to the surrounding environment. Empirical studies have shown that large patches provide more services than small patches (Tscharntke and Brandl 2004). However, small forest patches (1 hectare) can also support pollinators and increase pollination locally (Huais et al. 2020). Small forest patches in agricultural landscapes can accommodate diverse communities of pollinators and affect pollination locally (Proesmans et al. 2019). Proesmans et al. (2019) found that small forest patches positively affected pollination in a radius of $100 \mathrm{~m}$ around the patches. Therefore, even small and scattered patches can increase pollination locally.

Habitat amount has also been reported as a significant factor affecting the relationship between fragmentation and pollination. For example, high habitat amounts in a landscape result in species spillover from these natural habitats to the surrounding fields (Kammerer et al. 2016). When the habitat amount in a landscape is low, fragmentation forces pollinators to devote more energy to foraging (Maurer et al. 2020). Maurer et al. (2020) reported the adverse effects of fragmentation on 
A

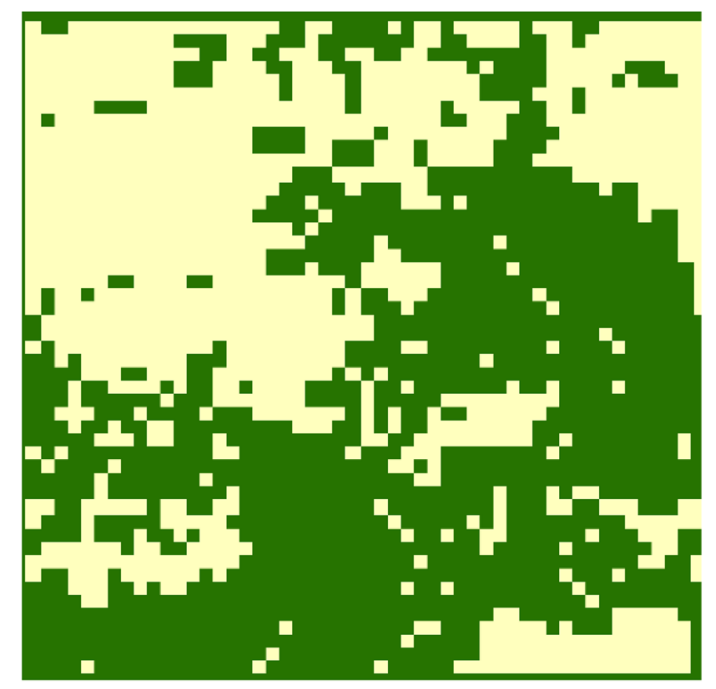

B

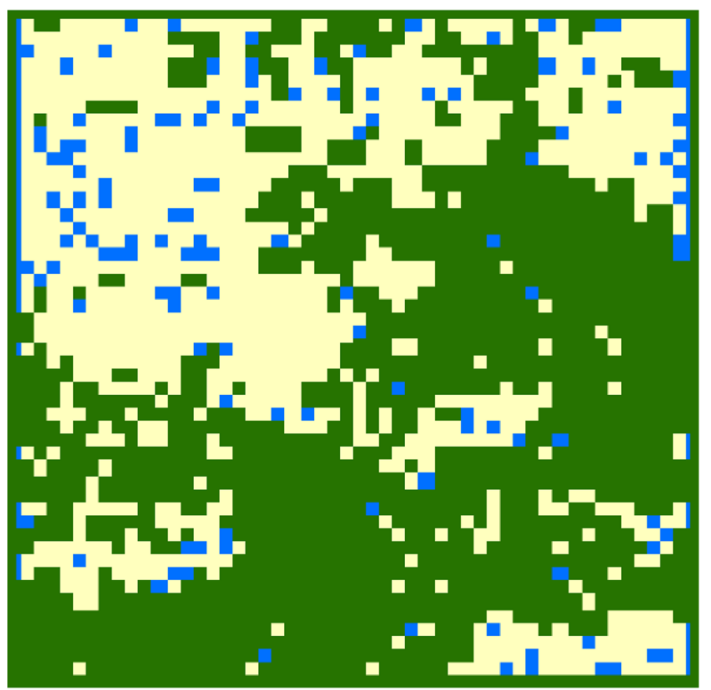

C

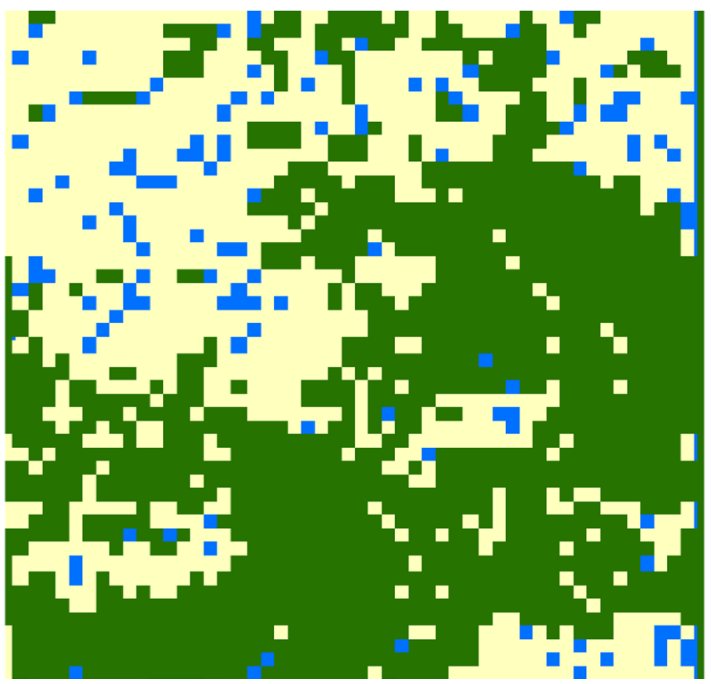

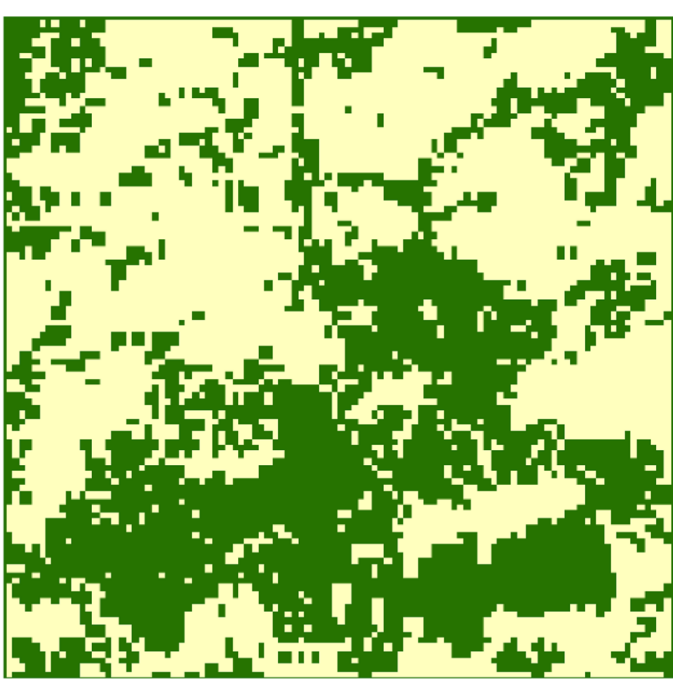

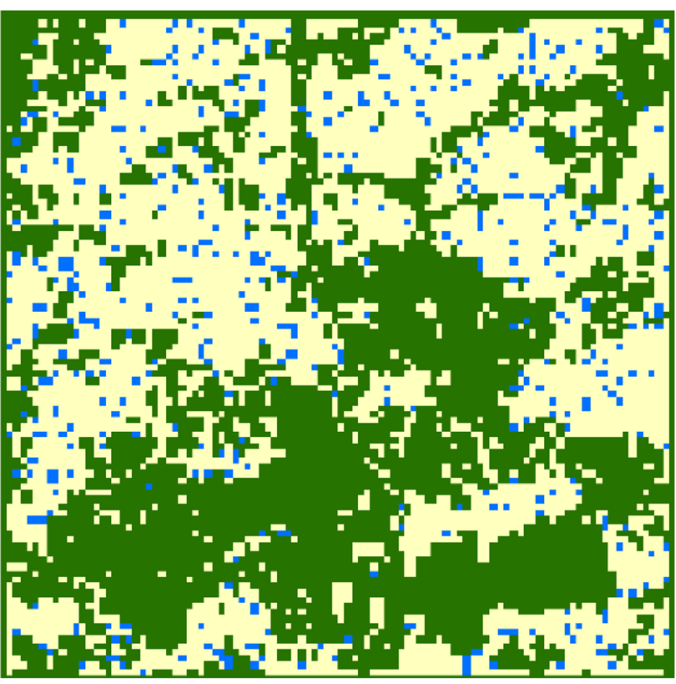

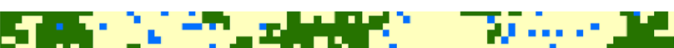

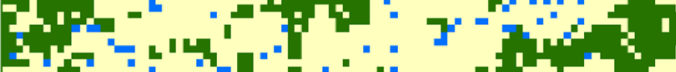

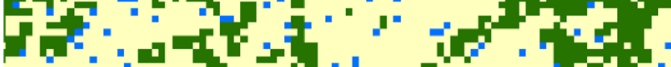

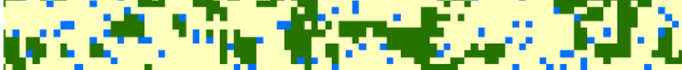
14

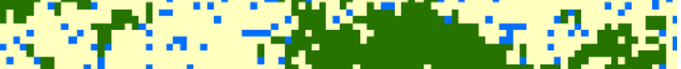
7.

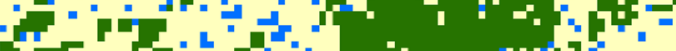
20.

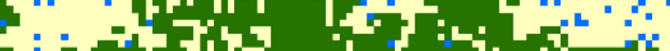

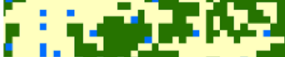
i

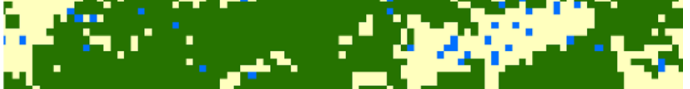
4.

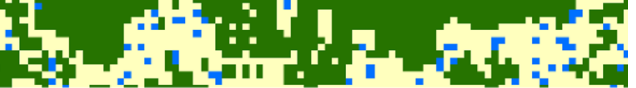

Fig. 3 Generated patches by a genetic algorithm at different $p$ in two subsets of the study area. Row $\mathbf{A}$ shows the original landscapes, and row $\mathbf{B}$ shows the created patches' location at $p=0.16$ that are located far away from original forest patches, and row $\mathbf{C}$ shows the created patches' location at $p=0.001$ that are located near the original forest patches. New patches are colored in orange 
bumblebee colony size at low habitat amounts and a positive effect at high habitat proportions. In contrast, landscapes with high amounts of habitat and a low degree of fragmentation have shown higher pollinator visitation (Schüepp et al. 2014). Everaars et al. (2018) found that the higher ratios of nesting habitat to foraging habitat resulted in the higher visiting rate in foraging habitat because fragmentation increased accessibility to nesting habitat. Maurer et al. (2020) argued that fragmentation could not be considered as a useful or adverse process because fragmentation was strongly dependent on habitat amount in the landscapes. They also found that increasing habitat amount and fragmentation positively affected pollination. However, in our study, this result was obtained only when the capacity of small patches to supply pollination was high. (i.e., $p>0.08$ ). In landscapes that small patches had low capacity in comparison to large patches (for example, $p=0.001$ ), we found that fragmentation effects were not dependent on habitat amount, and in all proportions, fragmentation negatively affected pollination. However, as the capacity of small patches increased, habitat amount became an affecting factor, which changed the effects of fragmentation on pollination, especially when forest proportions were less than 0.2 . Therefore, fragmentation can have both positive and negative effects on pollination (Fahrig 2017), depending on the capacity of small patches in supplying pollination.

\section{The effects of landscape structure on pollination}

Landscape metrics present more details about the effects of forest fragmentation on pollination. For example, our results showed that at $p<0.008$, the pollination decreased with an increase in the number of patches (NP). However, Joshi et al. (2016) showed that the higher number of patches increased pollination. They concluded that the higher number of patches increased the number of bees because these patches provide more nesting habitat and floral resources for the bees (Joshi et al. 2016). Our results showed that an increase in the number of patches increased pollination only in habitat amounts greater than 0.3 and at $p>0.08$.

The increase in the mean patch size (AREA-MN) in our study resulted in an increase in pollination that was consistent with the results of Joshi et al. (2016). Saturni et al. (2016) showed that forest cover had a positive effect on the diversity and abundance of bees. They reported that with increasing forest patches area, the diversity and abundance of bees increased. They also found that these effects varied at different scales, and bees' behavior was negatively affected by forest patch size on a small scale (Saturni et al. 2016). One reason is that in a landscape, only patches larger than a certain area can supply significant services to the surrounding environment. For coffee plants, for example, forest patches having an area of 60 hectares, are large enough to support a diverse population of pollinators to pollinate located fields (Ricketts et al. 2006). However, some studies have shown that orchid habitats with an area of fewer than 385 hectares are too small to maintain a population of pollinators (Pauw 2007). In our study, when increasing the capacity of small patches, AREA-MN showed a negative correlation with pollination.

In this study, we used the average distance between patches (ENN-MN) metric to measure the connectivity of forest patches. Fragmentation leads to an increase in this metric because patches are scattered around the landscape, and as a result, the distance between these patches increases. Our results showed that when small patches had minimal capacity to supply services, connectivity decreased pollination. Farwig et al. (2009) showed that pollination was inversely related to the isolation of forest patches, and the fragmented pattern of forest patches reduced the pollination rate. Boreux et al. (2013) also showed that the bees' abundance decreased with increasing distance from the nearest forest patches. In contrast, Mitchell et al. (2013) examined 69 articles related to the effects of connectivity on ecosystem services in detail. They found that $74 \%$ of these articles showed that connectivity increased pollination. For crops such as coffee and watermelon, the pollinators' abundance and visiting rates are less observed in highly isolated areas (Ricketts et al. 2006). For coffee plants, Bravo-Monroy et al. (2015), at distances of 0 to $800 \mathrm{~m}$ from forest patches, reported that proximity to the forest increases the abundance of bees. De Marco and Coelho (2004), at distances below $1 \mathrm{~km}$ showed that fields near forest patches had a $14 \%$ increase in yield, which was due to pollination. Ricketts et al. (2004) and Ricketts et al. (2006) found that bee diversity, visiting rate, and pollen accumulation rates were significantly higher in coffee fields near forest patches than in those farther away.

The complexity of the patches also had significant effects on pollination. To measure the shape and complexity of the patches, we used two metrics PAFRAC and ED. These metrics had different impacts on pollination in different forest proportions and $p$ values. High values of PAFRAC and ED imply that the shapes of the patches are complex. Our results showed that when small patches had little impact on the service provision, increasing edge density and shape complexity affected pollination negatively. Still, when the impact increased, shape complexity increased pollination, which was more notable in proportions greater than $30 \%$ of the total landscape. Increasing 
the patches' edge reduces accessibility to food and increases predators' presence (Betts et al. 2006). Small bees are sensitive to the edges and change their behavior due to the presence of predators (Hadley and Betts 2012). Reducing landscape complexity and increasing isolation also minimizes pollinators' diversity (Ferreira et al. 2013). Hass et al. (2018) found that landscapes with high edge densities of farms maintained more bees. The decreased visiting rate of bees with decreasing complexity on a small spatial scale has also been shown (Breitbach et al. 2012), although there was a very weak statistical relationship.

\section{The effect of spatial scale in increasing pollination}

In this part of the study, the most significant result was the effect of the spatial extent on the created patches' location that emphasizes the importance of investigating the effect of scale in ecological studies and pollination. The effect of spatial scale on pollinator activity has been practically studied in several studies, and it has often been stated that the pollinator population decreases with increasing spatial extent. For example, on a large scale (more than $500 \mathrm{~m}$ ) in heterogeneous landscapes, resources are redundant and have marginal effects on pollinators, as bees meet their needs without having to move over this distance (Joshi et al. 2016). In landscapes with low heterogeneity, bees have to travel longer distances.

The presence of additional habitats in a radius of $1750 \mathrm{~m}$ reduces the abundance of pollinators in small patches (Grass et al. 2018), probably because they leave small patches and move to larger patches with better food. Saturni et al. (2016) found that large bees were affected on a large scale and small bees on a small scale. Joshi et al. (2016) also showed that the effects of landscape configuration on bee visiting rate on small scales were more detectable for apple orchards. Optimal foraging theory also states that in a landscape, with uniform distribution of resource patches, bees travel near their nesting areas to reduce energy and time consumption and increase foraging efficiency (Heinrich 2004). Therefore, if the patches created to increase the pollination level are far away from the floral resources, they will not be useful. It can be concluded that the new patches should be scattered around the floral resources to reduce energy consumption, according to the theory. It is noteworthy that the creation of artificial nesting resources requires an examination of the situation before and after the creating of these patches for at least one year because it is difficult to identify whether the population of pollinators has increased (Dainese et al. 2018).

\section{Conclusion}

Understanding the habitat needs of pollinators helps us determine the amount and distribution of native habitats needed to ensure sustainable and adequate pollination on farms and across the landscape. Ideally, we should determine the efficiency of each pollinator for each particular crop and examine the behavior of the species in response to the landscape composition and configuration. The main purpose of this study was to determine an optimized pattern of new forest patches providing the highest pollination level in an agricultural landscape. The most important result from this study was that the effects of fragmentation on pollination were mainly dependent on the capacity of small patches in supplying pollination. The patches' capacity to supply pollination is not well studied and it is suggested that more studies be carried out in this field to determine the minimum habitat required for pollinating species. Habitat amount was another factor that changed the effects of fragmentation on pollination in some cases. These factors made it difficult, or almost impossible, to determine a specific pattern of forest patches to achieve the maximum possible pollination rate in an agricultural landscape. We showed that in creating new nesting habitats, special attention should be paid to the issue of spatial scale. In this study, only the behavior of bees was examined that were compatible with the exponential model, and it is necessary to investigate the results of other statistical models in this field.

Usage: $n l m \_$randomcluster (ncol, nrow, resolution $=1$, $\mathrm{p}$, ai $=\mathrm{c}(0.5,0.5)$, neighborhood $=4$, rescale $=$ TRUE) .

Our code: for (i in 1:100) $\{$ filename $=$ paste ('mypic_, i,' tiff').

random_cluster $<-$ nlm_randomcluster $(50,50,1,0.1$, $\mathrm{ai}=\mathrm{c}(0.25,0.25,0.5))$.

write Raster (random_cluster,filename $=$ file. Path ("my folder"), overwrite $=$ TRUE) $\}$.

\section{Abbreviations \\ NP: Number of patches; ENN-MN: Mean Euclidean Nearest-Neighbor Distance; Area-MN: Mean patch area; ED: Edge density; PAFRAC: Perimeter-area fractal dimension; Al: Aggregation index.}

\section{Acknowledgements}

The authors are thankful to Dr. Maghsoud Arshadi for helping in the programming part of the study.

\section{Authors' contributions}

ER has written the paper and has done the modeling part of the analysis. SB has reviewed the paper, helped to write, and interpreted the results. PD has reviewed the paper, edited grammar, and helped to respond to the paper's questions. All authors read and approved the final manuscript.

\section{Funding}

There are no financial conflicts of interest to disclose.

Availability of data and materials

Data are available on request from the authors only based on logical requests. 


\section{Code availability}

Code available on request from the authors only based on logical requests.

\section{Declarations}

Ethics approval and consent to participate

Not applicable.

\section{Consent for publication}

Not applicable.

\section{Competing interests}

The authors declare that they have no competing interests.

\section{Author details}

${ }^{1}$ Environmental Sciences Research Institute, Shahid Beheshti University, Tehran, Iran. ${ }^{2}$ Department of Geography and the Environment, University of North Texas, Denton, TX, USA.

Received: 2 March 2021 Accepted: 26 August 2021

Published online: 07 September 2021

\section{References}

Aguilar R, Ashworth L, Galetto L, Aizen MA (2006) Plant reproductive susceptibility to habitat fragmentation: review and synthesis through a metaanalysis. Ecol Lett 9(8):968-980

Aguirre A, Dirzo R (2008) Effects of fragmentation on pollinator abundance and fruit set of an abundant understory palm in a Mexican tropical forest. Biol Conserv 141(2):375-384

Assembly G (2015) Resolution adopted by the General Assembly on 19 September 2016, A/RES/71/1, 3 October 2016 (The New York Declaration).

Bailey S, Requier F, Nusillard B, Roberts SP, Potts SG, Bouget C (2014) Distance from forest edge affects bee pollinators in oilseed rape fields. Ecol Evol 4(4):370-380

Bentrup G, Hopwood J, Adamson NL, Vaughan M (2019) Temperate agroforestry systems and insect pollinators: a review. Forests 10(11):981

Betts MG, Forbes GJ, Diamond AW, Taylor PD (2006) Independent effects of fragmentation on forest songbirds: an organism-based approach. Ecol Appl 16(3):1076-1089

Blitzer EJ, Dormann CF, Holzschuh A, Klein AM, Rand TA, Tscharntke T (2012) Spillover of functionally important organisms between managed and natural habitats. Agric Ecosyst Environ 146(1):34-43

Boreux V, Krishnan S, Cheppudira KG, Ghazoul J (2013) Impact of forest fragments on bee visits and fruit set in rain-fed and irrigated coffee agroforests. Agric Ecosyst Environ 172:42-48

Bravo-Monroy L, Tzanopoulos J, Potts SG (2015) Ecological and social drivers of coffee pollination in Santander, Colombia. Agric Ecosyst Environ 211:145-154

Breitbach N, Tillmann S, Schleuning M, Grünewald C, Laube I, SteffanDewenter I, Böhning-Gaese K (2012) Influence of habitat complexity and landscape configuration on pollination and seed-dispersal interactions of wild cherry trees. Oecologia 168(2):425-437

Brosi BJ, Armsworth PR, Daily GC (2008a) Optimal design of agricultural landscapes for pollination services. Conserv Lett 1(1):27-36

Brosi BJ, Daily GC, Shih TM, Oviedo F, Durán G (2008b) The effects of forest fragmentation on bee communities in tropical countryside. J Appl Ecol 45(3):773-783

Bruinsma J (2009) The resource outlook to 2050: by how much do land, water use and crop yields need to increase by 2050. In: Expert meeting on how to feed the world in 2050, pp. 24-26

Craven D, Filotas E, Angers V, Messier C (2016) Evaluating resilience of tree communities in fragmented landscapes: linking functional response diversity with landscape connectivity. Diversity Distrib 22(5):505-518

Crossman N, Bernard F, Egoh B, Kalaba F, Lee N, Moolenaar S (2016) The role of ecological restoration and rehabilitation in production landscapes: an enhanced approach to sustainable development. Working paper for the UNCCD Global Land Outlook
Dainese M, Riedinger V, Holzschuh A, Kleijn D, Scheper J, Steffan-Dewenter I (2018) Managing trap-nesting bees as crop pollinators: spatiotemporal effects of floral resources and antagonists. J Appl Ecol 55(1):195-204

De Marco P, Coelho FM (2004) Services performed by the ecosystem: forest remnants influence agricultural cultures' pollination and production. Biodivers Conserv 13(7):1245-1255

Donaldson J, Nänni I, Zachariades C, Kemper J (2002) Effects of habitat fragmentation on pollinator diversity and plant reproductive success in renosterveld shrublands of South Africa. Conserv Biol 16(5):1267-1276

Eigenbrod F (2016) Redefining landscape structure for ecosystem services. Curr Landscape Ecol Rep 1(2):80-86

Ekroos J, Rundlöf M, Smith HG (2013) Trait-dependent responses of flowervisiting insects to distance to semi-natural grasslands and landscape heterogeneity. Landscape Ecol 28(7):1283-1292

Everaars J, Settele J, Dormann CF (2018) Fragmentation of nest and foraging habitat affects time budgets of solitary bees, their fitness and pollination services, depending on traits: results from an individual-based model. PLoS ONE 13(2):e0188269

Fahrig $L$ (2003) Effects of habitat fragmentation on biodiversity. Annu Rev Ecol Evol Syst 34(1):487-515

Fahrig $L$ (2017) Ecological responses to habitat fragmentation per se. Annu Rev Ecol Evol Syst 48:1-23

Fahrig L, Baudry J, Brotons L, Burel FG, Crist TO, Fuller RJ, Sirami C, Siriwardena GM, Martin JL (2011) Functional landscape heterogeneity and animal biodiversity in agricultural landscapes. Ecol Lett 14(2):101-112

Farwig N, Bailey D, Bochud E, Herrmann JD, Kindler E, Reusser N, Schüepp C, Schmidt-Entling MH (2009) Isolation from forest reduces pollination, seed predation and insect scavenging in Swiss farmland. Landscape Ecol 24(7):919-927

Ferreira PA, Boscolo D, Viana BF (2013) What do we know about the effects of landscape changes on plant-pollinator interaction networks? Ecol Indic 31:35-40

Gallai N, Salles JM, Settele J, Vaissière BE (2009) Economic valuation of the vulnerability of world agriculture confronted with pollinator decline. Ecol Econ 68(3):810-821

Gary NE, Witherell PC, Lorenzen K (1981) Effect of age on honey bee foraging distance and pollen collection. Environ Entomol 10(6):950-952

Gathmann A, Greiler HJ, Tscharntke T (1994) Trap-nesting bees and wasps colonizing set-aside fields: succession and body size, management by cutting and sowing. Oecologia 98(1):8-14

Grass I, Jauker B, Steffan-Dewenter I, Tscharntke T, Jauker F (2018) Past and potential future effects of habitat fragmentation on structure and stability of plant-pollinator and host-parasitoid networks. Nat Ecol Evol 2(9):1408-1417

Greenleaf SS, Williams NM, Winfree R, Kremen C (2007) Bee foraging ranges and their relationship to body size. Oecologia 153(3):589-596

Hadley AS, Betts MG (2012) The effects of landscape fragmentation on pollination dynamics: absence of evidence not evidence of absence. Biol Rev 87(3):526-544

Hass AL, Kormann UG, Tscharntke T, Clough Y, Baillod AB, Sirami C, Fahrig L, Martin JL, Baudry J, Bertrand C (2018) Landscape configurational heterogeneity by small-scale agriculture, not crop diversity, maintains pollinators and plant reproduction in western Europe. Proc R Soc B 285(1872):20172242

Häussler J, Sahlin U, Baey C, Smith HG, Clough Y (2017) Pollinator population size and pollination ecosystem service responses to enhancing floral and nesting resources. Ecol Evol 7(6):1898-1908

Heinrich B (2004) Bumblebee economics. Harvard University Press, Cambridge

Huais PY, Grilli G, Amarilla LD, Torres C, Fernández L, Galetto L (2020) Forest fragments influence pollination and yield of soybean crops in Chaco landscape. Basic Appl Ecol 48:61-72

Joshi NK, Otieno M, Rajotte EG, Fleischer SJ, Biddinger DJ (2016) Proximity to woodland and landscape structure drives pollinator visitation in apple orchard ecosystem. Front Ecol Evol 4:38

Kammerer MA, Biddinger DJ, Rajotte EG, Mortensen DA (2016) Local plant diversity across multiple habitats supports a diverse wild bee community in Pennsylvania apple orchards. Environ Entomol 45(1):32-38 
Keenan RJ, Reams GA, Achard F, de Freitas JV, Grainger A, Lindquist E (2015) Dynamics of global forest area: results from the FAO Global Forest Resources Assessment 2015. For Ecol Manag 352:9-20

Keitt TH (2009) Habitat conversion, extinction thresholds, and pollination services in agroecosystems. Ecol Appl 19(6):1561-1573

Klein AM, Steffan-Dewenter I, Tscharntke T (2003) Fruit set of highland coffee increases with the diversity of pollinating bees. Proc R Soc London 270(1518):955-961

Klein AM, Vaissiere BE, Cane JH, Steffan-Dewenter I, Cunningham SA, Kremen C, Tscharntke T (2007) Importance of pollinators in changing landscapes for world crops. Proc R Soc B 274(1608):303-313

Kline O, Joshi NK (2020) Mitigating the effects of habitat loss on solitary bees in agricultural ecosystems. Agriculture 10(4):115

Krishnan S, Kushalappa CG, Shaanker RU, Ghazoul J (2012) Status of pollinators and their efficiency in coffee fruit set in a fragmented landscape mosaic in South India. Basic Appl Ecol 13(3):277-285

Leitão AB, Miller J, Ahern J, McGarigal K (2012) Measuring landscapes: A planner's handbook. Island Press, Washington DC

Martins KT, Gonzalez A, Lechowicz MJ (2015) Pollination services are mediated by bee functional diversity and landscape context. Agric Ecosyst Environ 200:12-20

Matthews K, Buchan K, Sibbald A, Craw S (2006) Combining deliberative and computer-based methods for multi-objective land-use planning. Agric Syst 87(1):18-37

Maurer C, Bosco L, Klaus E, Cushman SA, Arlettaz R, Jacot A (2020) Habitat amount mediates the effect of fragmentation on a pollinator's reproductive performance, but not on its foraging behaviour. Oecologia. https:// doi.org/10.1007/s00442-020-04658-0

McGarigal K, Cushman SA, Neel MC, Ene E (2002) FRAGSTATS: spatial pattern analysis program for categorical maps. Computer software program produced by the authors at the University of Massachusetts, Amherst. Available at http://www.umass.edu/landeco/research/fragstats/fragstats. html.

Mitchell M (2014) The effects of landscape structure and biodiversity on ecosystem services. McGill University Libraries, Québec

Mitchell M, Crutchfield JP, Hraber PT (1994) Evolving cellular automata to perform computations: mechanisms and impediments. Physica D 75(1-3):361-391

Mitchell MG, Bennett EM, Gonzalez A (2013) Linking landscape connectivity and ecosystem service provision: current knowledge and research gaps. Ecosystems 16(5):894-908

Mitchell MG, Bennett EM, Gonzalez A (2014) Forest fragments modulate the provision of multiple ecosystem services. J Appl Ecol 51(4):909-918

Mitchell MG, Bennett EM, Gonzalez A (2015) Strong and nonlinear effects of fragmentation on ecosystem service provision at multiple scales. Environ Res Lett 10(9):094014

Munro NT, Fischer J, Wood J, Lindenmayer DB (2009) Revegetation in agricultural areas: the development of structural complexity and floristic diversity. Ecol Appl 19(5):1197-1210

Olsson O, Bolin A, Smith HG, Lonsdorf EV (2015) Modeling pollinating bee visitation rates in heterogeneous landscapes from foraging theory. Ecol Model 316:133-143

Pauw A (2007) Collapse of a pollination web in small conservation areas. Ecology 88(7):1759-1769

Potts SG, Roberts SP, Dean R, Marris G, Brown MA, Jones R, Neumann P, Settele $J$ (2010) Declines of managed honey bees and beekeepers in Europe. J Apic Res 49(1):15-22
Potts SG, Imperatriz-Fonseca V, Ngo HT, Aizen MA, Biesmeijer JC, Breeze TD, Dicks LV, Garibaldi LA, Hill R, Settele J (2016) Safeguarding pollinators and their values to human well-being. Nature 540(7632):220-229

Proesmans W, Bonte D, Smagghe G, Meeus I, Decocq G, Spicher F, Kolb A, Lemke I, Diekmann M, Bruun HH (2019) Small forest patches as pollinator habitat: oases in an agricultural desert? Landscape Ecol 34(3):487-501

Rahimi E, Barghjelveh S, Dong P (2021) Using the Lonsdorf model for estimating habitat loss and fragmentation effects on pollination service. Ecol Process 10:22

Ricketts TH, Daily GC, Ehrlich PR, Michener CD (2004) Economic value of tropical forest to coffee production. Proc Natl Acad Sci 101(34):12579-12582

Ricketts TH, Regetz J, Steffan-Dewenter I, Cunningham SA, Kremen C, Bogdanski A, Gemmill-Herren B, Greenleaf SS, Klein AM, Mayfield MM (2008) Landscape effects on crop pollination services: are there general patterns? Ecol Lett 11(5):499-515

Ricketts TH, Williams NM, Mayfield MM (2006) Connectivity and ecosystem services: crop pollination in agricultural landscapes. In: Crooks K, Sanjayan M (eds) Connectivity conservation. Cambridge University Press, New York, USA, pp 255-290

Rybicki J, Hanski I (2013) Species-area relationships and extinctions caused by habitat loss and fragmentation. Ecol Lett 16:27-38

Saturni FT, Jaffé R, Metzger JP (2016) Landscape structure influences bee community and coffee pollination at different spatial scales. Agr Ecosyst Environ 235:1-12

Schüepp C, Herzog F, Entling MH (2014) Disentangling multiple drivers of pollination in a landscape-scale experiment. Proc R Soci B 281(1774):20132667

Sciaini M, Fritsch M, Scherer C, Simpkins CE (2018) NLMR and landscapetools: An integrated environment for simulating and modifying neutral landscape models in R. Methods Ecol Evol 9(11):2240-2248

Steffan-Dewenter I (2002) Landscape context affects trap-nesting bees, wasps, and their natural enemies. Ecol Entomol 27(5):631-637

Steffan-Dewenter I, Schiele S (2008) Do resources or natural enemies drive bee population dynamics in fragmented habitats. Ecology 89(5):1375-1387

Syrbe RU, Walz U (2012) Spatial indicators for the assessment of ecosystem services: providing, benefiting and connecting areas and landscape metrics. Ecol Ind 21:80-88

Thomson JR, Moilanen A, Vesk P, Bennett AF, Nally RM (2009) Where and when to revegetate: a quantitative method for scheduling landscape reconstruction. Ecol Appl 19(4):817-828

Tscharntke T, Brandl R (2004) Plant-insect interactions in fragmented landscapes. Ann Rev Entomol 49(1):405-430

van Strien MJ, Slager CT, De VB, Grêt-Regamey A (2016) An improved neutral landscape model for recreating real landscapes and generating landscape series for spatial ecological simulations. Ecol Evol 6(11):3808-3821

Willmer PG, Cunnold H, Ballantyne G (2017) Insights from measuring pollen deposition: quantifying the pre-eminence of bees as flower visitors and effective pollinators. Arthropod Plant Interact 11(3):411-425

Zurbuchen A, Landert L, Klaiber J, Müller A, Hein S, Dorn S (2010) Maximum foraging ranges in solitary bees: only few individuals have the capability to cover long foraging distances. Biol Conserv 143(3):669-676

\section{Publisher's Note}

Springer Nature remains neutral with regard to jurisdictional claims in published maps and institutional affiliations. 